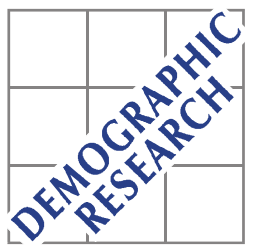

Demographic Research a free, expedited, online journal of peer-reviewed research and commentary in the population sciences published by the Max Planck Institute for Demographic Research Konrad-Zuse Str. 1, D-18057 Rostock · GERMANY www.demographic-research.org

DEMOGRAPHIC RESEARCH

VOLUME 23, ARTICLE 18, PAGES 509-530 PUBLISHED 03 SEPTEMBER 2010

http://www.demographic-research.org/Volumes/Vol23/18/

DOI: $10.4054 /$ DemRes.2010.23.18

Research Article

Patterns of asexuality in the United States

Dudley L. Poston, Jr.

Amanda K. Baumle

(C) 2010 Dudley L. Poston, Jr. \& Amanda K. Baumle.

This open-access work is published under the terms of the Creative Commons Attribution NonCommercial License 2.0 Germany, which permits use, reproduction \& distribution in any medium for non-commercial purposes, provided the original author(s) and source are given credit.

See http:// creativecommons.org/licenses/by-nc/2.0/de/ 


\section{Table of Contents}

1 Introduction $\quad 510$

$2 \quad$ Background 511

$2.1 \quad$ Asexual behavior $\quad 512$

2.2 Asexual desire 513

2.3 Asexual identity 513

$2.4 \quad$ Characteristics of asexuals $\quad 514$

2.5 Our analysis 515

3 Data and methods $\quad 516$

$4 \quad$ Results $\quad 519$

4.1 Prevalence of asexuals $\quad 519$

$\begin{array}{ll}4.2 & \text { Characteristics of asexuals } \\ 521\end{array}$

$\begin{array}{lll}5 & \text { Discussion and conclusion } & 526\end{array}$

$\begin{array}{ll}\text { References } & 529\end{array}$ 


\title{
Patterns of asexuality in the United States
}

\author{
Dudley L. Poston, Jr. ${ }^{1}$
}

\author{
Amanda K. Baumle ${ }^{2}$
}

\begin{abstract}
In this paper we use data from the 2002 National Survey of Family Growth (NSFG) to ascertain and analyze patterns of asexuality in the United States. We endeavor to extend the earlier work of Bogaert (2004) on this topic, which focused on patterns of asexuality in Great Britain. Using a social constructionist perspective to study asexuality, we conceptualize and measure the phenomenon in several ways, according to behavior, desire, and self-identification. We use the NSFG respondent sampling weights to produce several sets of unbiased estimates of the percentages of persons in the U.S. population, aged 15-44, who are asexual; each set is based on one or more of the various definitions of asexuality. Finally, we describe some of the characteristics of the asexual population using logistic regression.
\end{abstract}

\footnotetext{
${ }^{1}$ Department of Sociology, Texas A\&M University, College Station, TX 77843. E-mail: d-poston@tamu.edu.

${ }^{2}$ Department of Sociology, University of Houston, Houston, TX 77204. E-mail: akbaumle@uh.edu.
} 


\section{Introduction}

In recent years there has been an increase in demographic studies of sexuality. The resulting research has provided insights into broader population patterns of sexual behaviors, desires, and identities, and has emphasized the complexities inherent in the analysis of sexual outcomes. But with very few exceptions, none of the sexuality analyses have focused on asexuality, hence overlooking a sexuality dimension that may well characterize a not insignificant percentage of the population.

In this article, we examine data from the 2002 National Survey of Family Growth (NSFG) dealing with the prevalence and characteristics of asexual persons. Our research highlights the measurement and interpretation challenges that accompany demographic analyses of sexuality in general, and asexuality in particular. Recent research about sexual behaviors, desires, and identity has found that a small, but notable, number of individuals do not appear to fall clearly into the heterosexual, gay, or bisexual categories in terms of their sexuality. Rather, they report that they are not engaging in sexual activity, that they experience no sexual desire, and/or that they selfidentify as asexual (Bogaert 2004; Laumann et al. 1994). Asexuality has gained modest attention in the popular media as a sexual orientation (Sohn 2005; Jay 2005), but little quantitative and generalizable information is available about the prevalence of asexual identity or behavior in human populations or the characteristics associated with asexual persons. In the one quantitative study of which we are aware, Bogaert (2004) conducted a study of asexuality using nationally representative data, concluding that around 1.1 percent of the sampled British population provided an asexual response to a survey question on sexual desire.

Drawing on 2002 NSFG data, we seek to extend Bogaert's analysis in two ways. First, we explore whether similar patterns of asexuality are exhibited in the U.S. population as in the British population. In addition, and more importantly in terms of broader demographic studies of sexuality, we incorporate multiple dimensions of asexuality, in contrast to the single dimension permitted by Bogaert's data.

The limited literature on asexuality presents three kinds of definitions dealing with the phenomenon, namely, definitions based on one's behavior, one's desires, and one's self-identification. Our analysis of asexuality across these three dimensions highlights the manner in which both the prevalence and implications of asexuality vary depending on the dimension employed. Further, our analysis demonstrates some of the challenges faced by demographers using survey data on sexuality, as well as in crafting questions to explore population sexuality. 


\section{Background}

There is a limited social science literature on asexuality. This is due in part to the presumed low levels of asexuality in human and nonhuman populations. Asexuality is thought by some to be low because "one would expect strong selection pressures against such nonreproductive tendencies" (Bogaert 2004: 279). But the fact that a behavior has "nonreproductive tendencies" does not necessarily mean that it will have a low prevalence. Indeed Bogaert (2004: 279) has noted that homosexuality, i.e., "samesex attraction ... is clearly a nonreproductive orientation; ... [but] its prevalence over time and across societies continues to challenge evolutionary theorists."

Further, the prevalence of asexuality depends significantly on the manner in which asexuality is defined. As with other sexual identities, when behavior is the primary measure we would expect to see a higher prevalence of asexuality than if identity is the primary measure. In other words, individuals are more likely to not engage in sexual activity, than to identify as "asexual" (see Mosher et al. 2005; Laumann et al. 1994), suggesting that behavioral measures of sexuality may be expected to produce a higher prevalence than identity measures. Whether the primary component of asexuality is behavioral (a lack of sexual behavior), desire-based (a lack of sexual desire), or identity-based (labeling oneself as "asexual") is debatable. Indeed, even among those who identify as asexual, there is a lack of agreement regarding the degree to which an absence of sexual behavior or desire is a necessary component of asexuality (Prause and Graham 2007; Jay 2005; Westphal 2004).

The manner in which sexuality is defined depends, in part, on whether an essentialist or social constructionist perspective is employed (Foucault 1978; Butler 1990; Laumann et al. 1994; Katz 1995; Seidman 1996; Laumann et al. 1994). Founded in biology, the essentialist view holds that with regard to gay men and lesbians, for example, there is an essential characteristic common to all gay people that is distinct and separate from heterosexual people. This common feature or essence is thought to be a biological or psychological trait that establishes a person's inclusion into one of the two categories of gay or heterosexual (Laumann et al. 1994); the essentialist view thus assumes the existence of a binary categorization of humans. Applying this framework to an understanding of asexuality, one would posit that there is an essential biological or psychological characteristic that renders a person as asexual, thus resulting in the individual being classified as "asexual" rather than as "sexual."

The social constructionist view, on the other hand, counters and critiques the essentialist approach. For instance, with respect to gay men and lesbians, it argues against the notion of binary categories (Foucault 1978; Butler 1990; Seidman 1996) and suggests that sexual orientation exists along a continuum, with varying degrees of homosexuality/heterosexuality. Social constructionists have also noted that the 
concepts, definitions, and practices of gay individuals vary across context and cultures (Laumann et al. 1994; Katz 1995). These social constructionist arguments, we believe, are just as applicable to studies of asexuality. What is considered to be asexuality for one individual might not be so considered for another. One individual might selfidentify as an asexual, but still engage in sexual behavior. Conversely, another individual might define his or her asexuality as the abstention from sexual intercourse.

Due to such complexities, various researchers have emphasized the importance of examining identity, behavior, and desire in order to fully understand the diversity of sexuality (see e.g., SMART 2009; Baumle et al. 2009; Laumann et al. 1994). Indeed, in both social science research and in the popular media, asexuality has been defined by various authors on one or more of these three dimensions. We briefly explore definitions across these three dimensions in order to establish the importance of taking a broad approach in defining asexuality.

\subsection{Asexual behavior}

As previously noted, defining sexuality in terms of behavior typically results in a higher prevalence than in an identity definition and, in some cases, than a desire definition (Laumann et al. 1994; Kinsey et al. 1948). Behavioral definitions have been used in empirical studies of asexuality for both human and nonhuman populations. According to Rothblum and Brehony (1993), asexuals are typically viewed as individuals who have "engaged in few or no sexual behaviors," and this may have occurred either by choice, or as a consequence of an external force. For example, some lesbian relationships have been described as "asexual" due to a focus on partnership and romance, rather than sexual interaction (Rothblum and Brehony 1993); approximately half of lesbians in long-term relationships have been found to engage in infrequent or no sexual interaction (Blumstein and Schwartz 1983). Further, behavioral asexuality, i.e., celibacy, is often a characteristic of many members of religious sects (Cozzens 2006; Abbott 2001), and some other groups, for instance, athletes and professional women. Behavioral asexuality is also more prevalent, and often assumed, for individuals with disabilities and for the elderly (Deacon, Minichiello, and Plummer 1995; Milligan and Neufeldt 2001).

Studies have attempted to quantify the prevalence of behavioral asexuality in animal populations. For example, sheep studies conducted in the 1990s sought to determine the preferences of sheep for sexual partners. Most of the rams selected ewes for their mates, but about $10 \%$ of the rams showed no interest in the ewes (Westphal 2004). These rams were then placed in pens with either two rams or two ewes. Between $5-7 \%$ of the rams attempted to interact sexually with other rams, but $2-3 \%$ continued to 
show no interest in either males or females (Westphal 2004). These rams were classified as "asexual" by virtue of their behavior.

Studies of humans have also explored the prevalence of individuals engaging in few or no sexual behaviors. Mosher and colleagues (2005) found that approximately 10 $\%$ of males and $8 \%$ of females aged $15-44$ had never had vaginal, oral, or anal heterosexual sex in their lives. Laumann and colleagues (1994) found that approximately $3.4 \%$ of men and $2.5 \%$ of women had not had a heterosexual sex partner since the age of eighteen. These individuals could be considered behaviorally asexual with respect to heterosexual sex, even though we have no indication that they would remain so throughout their lives.

\subsection{Asexual desire}

Asexuality may also be defined as an absence of sexual desire, regardless of sexual behavior. Indeed, the Asexual Visibility and Education Network (“AVEN") (Jay 2005) holds that an independence from sexual desire is the key feature of asexuality, claiming that "an asexual is someone who does not experience sexual attraction." Asexuals might choose to develop an emotional closeness to particular individuals that is devoid of sexual contact (Jay 2005; Westphal 2004; Rothblum and Brehony 1993). Or, they might engage in sexual behavior, but experience no desire or pleasure in the act (Prause and Graham 2007).

At least two empirical studies have assessed the prevalence of asexuality via a desire measurement. Drawing on data from a nonrandom sample of 689 individuals, Nurius (1983) found that approximately $5 \%$ of the men and $10 \%$ of the women did not report feeling sexual attraction for either men or women; Nurius classified these individuals as "asexual."

Bogaert's (2004) nationally representative study of asexuality examined the prevalence of asexual desire in Great Britain. Drawing on a survey of 18,876 respondents in England, Wales, and Scotland, he found that approximately $1.1 \%$ of the sample indicated that they "have never felt sexually attracted to anyone at all" (Bogaert 2004: 281). He classified these individuals as "asexual," in contrast to "sexual" individuals.

\subsection{Asexual identity}

Measures of sexual identity often generate a lower prevalence rate of sexual groups. For example, many individuals might experience same-sex sexual attraction, or even engage 
in same-sex sexual behaviors, but still identify as "heterosexual" (Prause and Graham 2007; Laumann et al. 1994; Kinsey et al. 1948). Individuals at the Asexual Visibility and Education Network (AVEN) have described identifying as asexual as follows:

There is no litmus test to determine if someone is asexual. Asexuality is like any other identity-at its core, it's just a word that people use to help figure themselves out. If at any point someone finds the word asexual useful to describe themselves, we encourage them to use it for as long as it makes sense to do so (Jay 2005).

Often, one's asexual identity is used in tandem with one or both of the other dimensions of sexuality. For example, some individuals might select the identity even if they experience sexual desire, if they are using "asexuality" to describe a state of abstinence (Abbott 2001). In one nonrandom survey, only 17 of the $41(41.5 \%)$ individuals identifying as asexual reported that they were not attracted to men or women (Prause and Graham 2007). Of the 19 individuals in this nonrandom sample who reported having no sexual attraction to men or women, however, $90 \%$ identified as asexual. Thus, these findings seem to suggest that asexual could be a common identifier for those who experience no sexual attraction to men or women, but that the selection of an asexual identity does not necessarily imply a lack of sexual attraction.

Further, an asexual identity does not necessarily communicate a lack of sexual behavior. This identity could be employed by those who engage in sexual behavior, but do not experience sexual desire. Prause and Graham (2007: 345) found in their interviews of four asexuals, that "the defining feature of asexuality for these individuals appeared to be a lack of sexual interest or desire, rather than a lack of sexual experience."

Thus, for some, asexuality may be an identity, used as a signal to others of a chosen lifestyle. The asexual identification is sometimes used during the "coming out" process, to inform family and friends of a selected sexual orientation (Westphal 2004; Prause and Graham 2003). The adoption of the asexual identity has taken many forms, including the development of online communities centered around the label, the creation of asexuality-related merchandise ("A-pride" t-shirts, for example), and the development of literature on asexuality (Westphal 2004; see also Jay 2005).

\subsection{Characteristics of asexuals}

Asexuals have been found to differ from sexuals on various demographic characteristics. In his study in Great Britain, Bogaert (2004) estimated multivariate 
logistic regression equations separately for males and females where the dependent variable was sexual attraction (asexual $=1$ ). He found asexuals to be slightly older than sexuals (see also, Prause and Graham 2007), and that significantly more women than men reported being asexual (however, Prause and Graham found no significant sex difference in their nonrandom survey). Bogaert also found that compared to sexuals, asexuals had lower average socioeconomic status, and they were less well-educated. In Prause and Graham's sample, on the other hand, asexuals reported higher levels of education than sexuals. Bogaert also found that asexuals were "more likely to have adverse health" (2004: 282), were shorter, and weighed less than sexuals. Finally, those classified as asexual attended religious services more frequently. These results led Bogaert to suggest that "there may be a number of independent developmental pathways, perhaps both biological and psychosocial, leading to asexuality. [Also] ... physical development factors that are independent of general debilitating illnesses (which may have lower sex drive or interest) may affect growth and development mechanisms related to sexual orientation" (Bogaert 2004: 284).

In terms of sexual behavior and relationships, asexuals have been found to differ significantly from sexuals. Studies have found that asexuals have fewer sex partners and less frequent sexual activity than sexuals; some are reported to be celibate (Prause and Graham 2007; Bogaert 2004). Fewer asexuals than sexuals reported being in, or having had, long-term relationships (Bogaert 2004); however, some "were currently in or had had long term cohabiting or marital relationships" (2004: 282). Individuals in marital relationships could be behaviorally asexual as a consequence of absent partners (e.g., spouses in the military or in prison).

We have mentioned celibacy as a behavioral characteristic of asexuals. Some studies dealing with celibacy and asexuality have explored the emotional well-being of celibates. Abbott (2001) examined the history of celibacy over the past 3,000 years and found that more were happy and satisfied, than not, with their lack of sexual activity, even though most celibates self-identify as sexuals (see especially her discussion in chapter 13 on "the New Celibacy"). Similarly, in a study of clerical celibacy, Cozzens (2006) has noted that Catholic priests who view their celibacy as a charism, a bestowed gift from the Holy Spirit, are more often very happy, rather than not very happy, with their sexual celibacy. In Prause and Graham's (2007) analysis of asexuals, they found no significant differences between asexuals and sexuals in terms of concerns regarding their level of sexual desire, or in regard to their interest in speaking to a health professional regarding their sexuality. 


\subsection{Our analysis}

As already noted, Bogaert's (2004) analysis was the first nationally representative study of asexuality that endeavored to both estimate its prevalence in the population and identify some of the major factors associated with its incidence. He made several important points that provide support for the approach we undertake here. First, he noted that some researchers may be concerned about his using a definition of asexuality based only on attraction or desire. He stated that analyses using other definitions of asexuality, including behavior and self-identification, need to be undertaken "to increase reliability of measurement and to expand [his current] research" (2004: 285). He observed also that his sample respondents were drawn from "only a small region of the Western world, England, Wales and Scotland ... [and that perhaps] other Western nations may exhibit different patterns of asexuality" (2004: 285).

In our study we use Bogaert's findings as benchmarks regarding the prevalence of asexuality and the characteristics of asexuals compared to sexuals. Also, we hope that our investigation of asexuality in the U.S. will begin to address some of the issues raised in his article, as well as in the other studies discussed above. Specifically, we employ a definition of asexuality which uses data on behavior, identification, and desire, to see the manner in which asexuality in particular - and sexuality in general might vary across these three dimensions.

\section{Data and methods}

The 2002 National Survey of Family Growth is the sixth cycle of surveys of family growth conducted by the U.S. National Center for Health Statistics. ${ }^{3}$ The 2002 NSFG is a nationally representative multistage survey of male and female respondents between the ages of 15 and 44. Interviews were conducted in person between January 2002 and March 2003. The sample is comprised of 12,571 Americans (7,643 women and 4,928 men). The data addressing sensitive topics, such as those dealing with sexuality, were collected using Audio Computer-Assisted Self-Interviewing (ACASI) "in which the respondent listens to the questions through headphones, reads them on the screen, or both, and enters the response directly into the computer ... and yielded more complete reporting of sensitive behaviors" (Mosher et al. 2005: 7-8). The survey had an overall response rate of $79 \%$ ( $80 \%$ for women and $78 \%$ for men).

\footnotetext{
${ }^{3}$ Prior surveys were conducted in 1973, 1976, 1982, 1988, and 1995, and an additional survey was conducted in 2006-08 (data not yet fully available). The 2002 NSFG is the first to include male respondents (National Center for Health Statistics 2004), thus opening the door for comparative research based on sex.
} 
We used two questions in the 2002 NSFG to obtain respondent data on the behavioral dimension of asexuality and they are slightly different for males and females. They ask each male 1) if he has ever had vaginal sex with a female, and 2) if he has ever had oral or anal sex with a male. The two female questions ask 1) if the female has ever had vaginal sex with a male, and 2) if she has ever had sexual contact with a female.

A respondent answering no to both questions would be categorized by us as asexual on the behavioral dimension. We accentuate the point that this is solely a classification according to the behavioral dimension, and might both overestimate and underestimate asexuality. Individuals who have not yet engaged in sexual intercourse due to age, lack of partners, or religious reasons, would be classified as "asexual" under this measure; these individuals might fully intend to engage in sexual behavior at some point later in their lives. Further, these individuals might experience sexual desire and/or identify with a sexual orientation other than asexual (e.g., members of religious orders who are celibate and hence do not engage in sexual behavior, but likely experience sexual desire and identify as heterosexual or homosexual).

In addition to being an overinclusive measure of asexuality, according to some definitions, we note that the behavioral measure will also fail to capture some individuals who might be considered asexual on either the desire or identification measures. Individuals who have had sexual intercourse with men or women at some point in their life, but who have not engaged in sexual behavior for most of their life, would still be classified as "sexual" on the behavioral measure. Further, those who engage in regular sexual behavior, but do not experience sexual desire or who identify as asexual would also be classified as "sexual" on this measure.

With respect to the next dimension, namely, the self-identification of sexual orientation, the 2002 NSFG asked each respondent the following question: Do you think of yourself as heterosexual, homosexual, bisexual or something else? It is possible that an asexual might choose to identify along any of these proffered categories, depending on whether their asexuality is primarily behavioral, based on desire, or based on identity. For example, someone who engages in sex with persons of the opposite sex, but feels no desire, might be "asexual;" s/he could well identify, however, as heterosexual given his or her sexual behavior. Nonetheless, we would anticipate that those who are choosing asexuality as an identity (which might or might not correspond with their behavior or desire) would choose the "something else" response.

However, we agree with Mosher and his colleagues that "further study of those who answered 'something else' ... is needed ... to better characterize their sexual and risk behaviors" (Mosher et al. 2005: 14). In fact, the "something else" response would also be the likely answer for any person not identifying as heterosexual, homosexual, or bisexual - whether that be as gay, lesbian, queer, dyke, zoosexual (Earls and Lalumiere 
2009), masochist, exhibitionist, or fetishist. These issues notwithstanding, the "something else" response would be the most appropriate response for persons selfidentifying as asexual. Thus the number of cases enumerated in the "something else" response category would include self-identified asexuals; the category is, nonetheless, overinclusive in terms of capturing individuals other than asexuals.

With respect to sexual desire and attraction, the 2002 NSFG asked each respondent the following question: People are different in their sexual attraction to other people. Which best describes your feelings? Are you...Only attracted to the opposite sex; Mostly attracted to the opposite sex; Equally attracted to the opposite sex and the same sex; Mostly attracted to the same sex; Only attracted to the same sex; Not sure.

We suggest that a person who does not experience sexual desire for other persons would probably answer the above question as "not sure." There is no specific response on the 2002 NSFG question on sexual attraction for persons who are not attracted sexually to other men and/or women. A response category such as "I am not sexually attracted to anyone at all" would be the preferred response, but there was no such response available on the 2002 NSFG. We believe that persons not desiring sex with other people would use the "not sure" response, or, perhaps, would not answer the question. Similarly, persons only desiring sex with, or only being sexually attracted to, animals, or receiving sexual gratification from exhibitionism or other paraphilias, would also likely answer the 2002 NSFG question on sexual desire as "not sure." Further, the "not sure" response would be the selected response for individuals who felt unable to categorize their sexual attraction as "mostly" male or female. Although the "not sure" response would likely be the answer for persons who do not desire sex with other persons, it would also be the response for some other persons as well and is, therefore, overinclusive in this regard.

In our paper, we report estimates of the U.S. male and female population aged 15 to 44 who provide the so-called "asexual response" to each of the above questions on behavior, self-identification, and desire. These estimates of asexuality based on the selfidentification and the desire questions, however, will likely be over-estimates, given that the response categories most probably include both asexuals as well as other individuals. Further, the behavioral measure is both over- and under-inclusive, for the reasons suggested above.

In addition to our three measures of asexuality, we include in our analyses various demographic characteristics found to be predictive of sexual behavior. We use nine independent variables to analyze the characteristics of asexuals compared to sexuals; we parallel our analyses as closely as possible with that of Bogaert (2004). As described above in our review of the literature, the included variables have been found to be predictive of asexual responses (Prause and Graham 2007; Cozzens 2006; Bogaert 2004; Abbott 2001). Our independent variables are the following: whether the 
respondent resides in a nonmetropolitan area (yes or no), whether the respondent is a full-time worker (yes or no), the highest school grade completed, self-reported health condition (from 1 = excellent to 5 = poor), height (in inches), weight (in pounds), age (in years), whether the respondent has ever been married (yes or no), and whether the respondent has ever cohabited (yes or no).

Drawing on Bogaert's (2004) and Prause and Graham's (2007) findings, we hypothesize that asexuals (in any category) compared to sexuals should be more likely to reside in nonmetropolitan areas, and should be older. Compared to sexuals, they should be less likely to be full-time workers, have less education, not be as healthy, be shorter and lighter, and be less likely to have been married, and less likely to have evercohabited. We turn now to the results of our analysis.

\section{Results}

\subsection{Prevalence of asexuals}

Table 1 (top panel) presents data on the percentages of females and males in the United States aged 15 to 44 according to the categories of each of the three types of asexuality, namely, whether they have ever had sexual activity, either same-sex sex or opposite-sex sex, in their lifetimes; their specific response to the NSFG question on sexual attraction (see above); and their self-identified sexual orientation (see above). In our analyses of these data, we used statistical sample adjustment methods ("svy") available in the Stata 11 statistical package (Stata Corp 2009) that introduce survey adjustment estimators to adjust our analyses according to the population weights and clustering in the 2002 NSFG.

We find that almost $5 \%$ of the females and more than $6 \%$ of the males report that they have never had sex in their lifetimes. With respect to sexual attraction, almost $1 \%$ each of both the females $(0.8 \%)$ and the males $(0.7 \%)$ are "not sure" about their sexual attraction. We argued above that this would be the likely response of persons who are not sexually attracted to either males or females, although the category would include other individuals as well.

Finally, with regard to self-identified sexual orientation, the weighted percentage data in Table 1 (bottom panel) of females and males giving the "something else" response to the question on sexual orientation are $3.8 \%$ and $3.9 \%$, respectively. As we have already noted, although persons self-identifying as asexuals would be among those respondents selecting the "something else" response, we do not know the proportion of those identifying as "something else" who are, in fact, asexuals. All we can surmise is 
the high likelihood that the "something else" response would be the response for selfidentified asexuals.

To explore the intersection of these three dimensions of sexuality in greater detail, we combine the asexuality responses to the above NSFG questions into seven possible outcomes: providing the so-called "asexual" response (1) only to identification, (2) only to desire, (3) only to behavior, (4) to both identification and desire, (5) to both identification and behavior, (6) to both desire and behavior, and (7) to identification, desire, and behavior. Weighted percentages for U.S. females and males aged 15 to 44 are shown in Figures 1 and 2.

Table 1: Weighted percentages of females and males (15 to 44 years of age) by whether they have ever had opposite-sex sex or same-sex sex in their lifetimes, by sexual attraction, and by self-identified sexual orientation: 4,270 males and 6,821 females, United States, 2002

EVER HAD SEX IN LIFETIME

No Yes

Females

Males

4.8

6.1

95.2

93.9

CATEGORIES OF SEXUAL ATTRACTION

\begin{tabular}{llllll} 
O-M & $M-M$ & B & M-F & O-F & NS \\
\hline
\end{tabular}

Females

85.7

92.2

10.2

1.9

0.8

0.7

0.8

Males

3.9

1.0

0.7

1.5

0.7

CATEGORY LABELS

O-M: Only Males; M-M: Mostly Males; B: Both Sexes; M-F: Mostly Females;

O-F: Only Females; NS: Not Sure

\begin{tabular}{lccccc}
\multicolumn{5}{c}{ CATEGORIES OF SEXUAL ORIENTATION } \\
& HET & HOMO & BI & SE & NR \\
\cline { 2 - 6 } & & & & & \\
Females & 90.3 & 1.3 & 2.8 & 3.8 & 1.8 \\
Males & 90.2 & 2.3 & 1.8 & 3.9 & 1.8 \\
CATEGORY LABELS \\
$\quad$ HET: Heterosexual; HOMO: Homosexual; BI: Bisexual; SE: Something Else; \\
$\quad$ NR: Did Not Report
\end{tabular}

Of all the respondents giving an "asexual" response to any one of the three questions, only $0.6 \%$ of the females and $0.9 \%$ of the males gave the asexual response on all three dimensions. For both females and males, by far the largest percentage is 
found in the "only behavior" category. That is, $51.3 \%$ of the females and $56.6 \%$ of the males giving an "asexual" response to the NSFG question or questions on any one of the three asexual dimensions, gave the response only to the questions pertaining to having no sexual activity ever in their lifetimes. Slightly more than $38 \%$ of the females and almost $34 \%$ of the males gave the "asexual" response only to the question of selfidentification (the "something else" answer). And only $3.7 \%$ of the females and $4.3 \%$ of the males gave the "asexual" response only to the question on desire.

\subsection{Characteristics of asexuals}

We now use logistic regression models to examine whether the characteristics of asexuals differ from those of sexuals. When Bogaert (2004) examined the characteristics of persons classified as asexual in his survey of Great Britain respondents, he estimated a logistic regression equation predicting the log odds of being asexual using numerous independent variables measuring the characteristics of the respondents. We use a similar strategy here. In Table 1, we have categorized the female and male respondents as sexual and as asexual according to the three dimensions of behavior, desire/attraction, and orientation. We thus estimate separately for females and for males three logistic regression equations according to each of these dimensions. Although we show in Figures 1 and 2 more detailed cross-classifications of asexuals and sexuals by mixing and matching simultaneously each person's responses with regard to each of the three dimensions, the numbers of cases in many of the crossclassified categories are much too small for separate regression analysis.

In our logistic regression analyses our dependent variable has two responses, namely, whether the person is asexual (scored 1) or sexual (scored 0). We include nine independent variables, as described in earlier paragraphs. The logistic regression equation generates for each independent variable the independent log odds according to the independent variable of interest of being asexual versus being sexual. In Tables 2 and 3 reporting the results of the logistic regressions, we have exponentiated the logit regression coefficients into odds ratios. And as already noted, we used sample adjustment methods (i.e., Stata's "svy" methods) to adjust our analyses according to the population weights and clustering in the 2002 NSFG.

We note that our logistic regression analyses, like the logistic regression analysis of Bogaert, are meant to describe the characteristics of asexuals and sexuals. We are not using the independent variables in the logistic regression equations to predict the likelihood of a person being asexual versus sexual. We are using this statistical method simply to determine on which characteristics asexuals are significantly different from sexuals, and on which characteristics they are not. 
Figure 1: Interrelations of components of asexuality for U.S. females 628 females (9.2\% of total sample), U.S, 2002

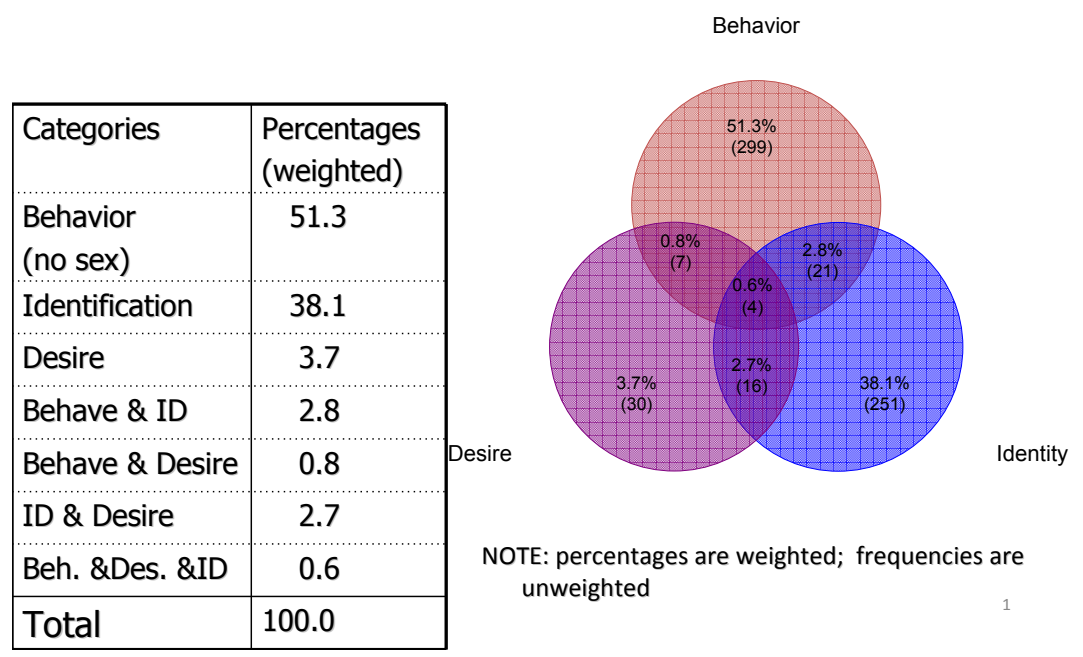

Figure 2: Interrelations of components of asexuality for U.S. males 507 males (11.9\% of total sample), U.S, 2002

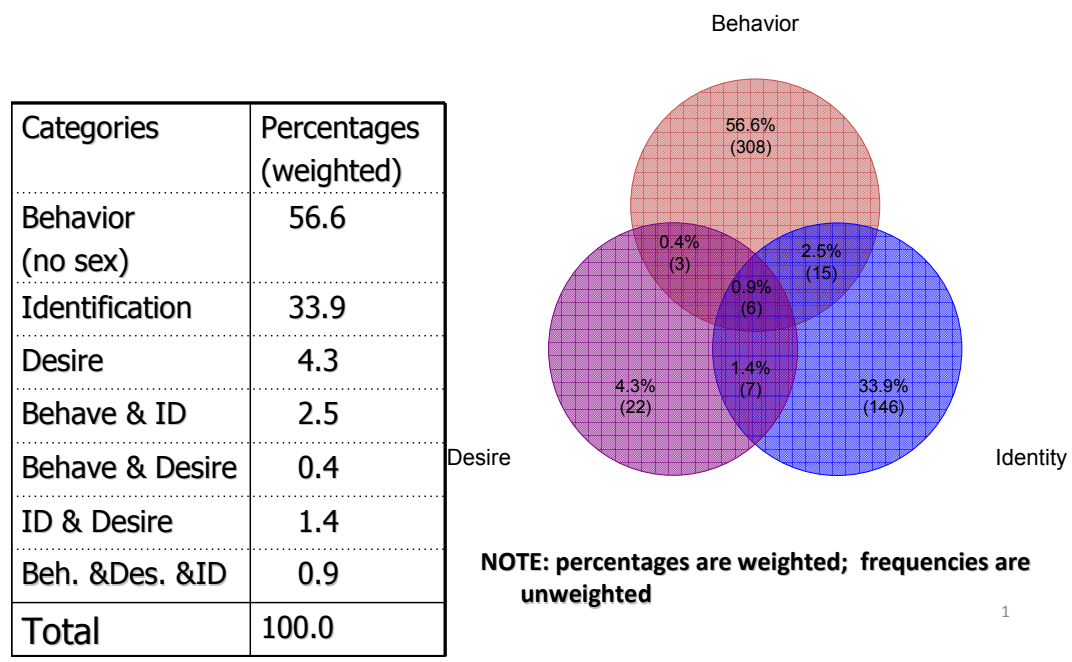


We report for females and males separately the odds ratios from three logistic regression equations predicting the odds of being an asexual versus being a sexual according to each of the three dimensions of sexuality. The odds ratios are provided for each of the nine independent variables. In the first (text) column of the two tables, to the immediate right of each independent variable is a positive or negative sign indicating the hypothesized direction of the relationship of that variable with the odds of being asexual (Tables 2 and 3). We have asterisked the odds ratios that are statistically significant at $\mathrm{p}<.05$.

Table 2: Odds Ratios from Logistic Regression Equations of Three Different Dimensions of Asexuality (Behavior, Attraction, and Identification) on Selected Socioeconomic and Physical Variables: 6,821 Females Aged 15-44, United States, 2002

\begin{tabular}{|c|c|c|c|}
\hline & ASEXUALITY DIME & SION (COMPAREL & SEXUAL) \\
\hline & BEHAVIOR & ATTRACTION & IDENTIFICATION \\
\hline Independent Variable & & & \\
\hline Nonmetro Residence $(-)^{\star *}$ & 0.75 & 0.64 & $1.51^{*}$ \\
\hline Full-time Work $(-)^{\star *}$ & $0.67^{*}$ & 1.00 & 0.80 \\
\hline Education (-) & $0.88^{*}$ & 0.98 & $0.73^{*}$ \\
\hline Health Condition $(+)^{\star * *}$ & 0.99 & $2.09^{*}$ & $1.28^{*}$ \\
\hline Height (inches) (-) & $0.92^{*}$ & 0.98 & 1.03 \\
\hline Weight (pounds) (-) & 1.00 & 1.00 & 1.00 \\
\hline Age $(+)$ & 1.00 & 0.98 & 1.00 \\
\hline Ever Married $(-)^{\star *}$ & $0.10^{*}$ & 0.75 & 0.71 \\
\hline Ever Cohabited $(-)^{* *}$ & $1.67^{*}$ & 1.02 & 0.94 \\
\hline F-test & $(9,6812)=41.16^{*}$ & $(9,6812)=4.27^{*}$ & $(9,6812)=17.46^{*}$ \\
\hline
\end{tabular}

Table 2 presents the logistic regression results for females. Consider, for example, the statistically significant odds ratio of 0.67 near the top of column 2 that is labeled BEVAVIOR; this is the exponentiated coefficient for the full-time work dummy variable among those who gave the "asexual" response on the behavior dimension of sexuality. This odds ratio of 0.67 means that the odds of full-time workers being asexual versus being sexual are $33 \%$ less than those of part-time workers, according to the behavior dimension, that is $(0.67-1) * 100=-33 \%$. Thus individuals who are asexual in their behavior are less likely than sexuals to be full-time workers, as 
hypothesized. Next consider the third coefficient in this column, 0.88 for education; this means that among the respondents, for every one year increase in completed education, there is a $12 \%$ reduction in the odds of being a behavioral asexual versus being a sexual, that is $(0.88-1) * 100=-12 \%$. As hypothesized, on the behavioral dimension of sexuality, asexuals are less educated than sexuals.

In two of the three logistic regressions in Table 2 comparing asexuals with sexuals, education has a significant and negative effect on the likelihood of being an asexual. This indicates that in two of the dimensions of sexuality, namely, behavior and selfidentification, asexuals are less educated than sexuals. In addition to education, there are two statistically significant coefficients for the health conditions variable. This variable is coded so that $1=$ excellent health and $5=$ poor health; thus, the positive coefficients indicate that asexuals are less healthy than sexuals. These two statistically significant and positive coefficients are, notably, present for those who identified as asexual on the attraction/desire dimension, and on the self-identification dimension. It is possible that this finding indicates that poor health reduces sexual desire, producing an asexual response (see the research on asexuality and disability by Milligan and Neufeldt [2001]).

The two characteristics of education and health conditions are the only ones of the nine independent variables used in the equations reported in Table 2 with statistically significant coefficients in two of the three regression equations. None of the nine coefficients are significant in all three equations. Several of the characteristics have statistically significant effects on the odds of being asexual in only one of the equations: nonmetropolitan residence is significant, but in the wrong direction, in the "identification" equation; full-time work, height, and ever-married are significant only in the "behavior" equation; finally, ever-cohabited is significant, but in the wrong direction, in the "behavior" equation.

There are no differences between asexual and sexual females on the remaining characteristics in the other equations. There are no differences between them with regard to weight and age, a finding comparable to that in Bogaert's analysis.

Among females we find that the major characteristics differentiating asexuals from sexuals are education and health. As already noted, the importance of this latter characteristic suggests that poor health might serve as a partial explanation for some asexual behaviors. We now turn to an examination of the logistic regression results for males.

Table 3 shows odds ratios for U.S. males. It is apparent that the characteristics of asexuals and sexuals seem to vary in somewhat similar and in differing ways for males, as compared to females. In the first place fewer characteristics differentiate asexuals from sexuals for males compared to females. There are nine statistically significant coefficients in the female equations (Table 2), but only five in the male equations 
(Table 3). However, this difference is due in part to perfect statistical prediction for two of the independent variables. Note that the "behavior" equation for males (the $1^{\text {st }}$ data column in Table 3) only includes seven independent variables; the ever-married and ever-cohabited have been omitted as independent variables. This occurs because none of the 337 respondents who never had sex in their lifetimes had ever-cohabited or were ever-married; in this sense these two characteristics perfectly predict the asexual category. Had we been able statistically to include them in the equation, there would have been seven, not five, statistically significant effects in the male equations shown in Table 3.

Table 3: $\quad$ Odds Ratios from Three Logistic Regression Equations of Three Different Dimensions of Asexuality (Behavior, Attraction, and Identification) on Selected Socioeconomic and Physical Variables: 4,270 Males Aged 15-44, United States, 2002 ASEXUALITY DIMENSION (COMPARED TO SEXUAL)

\begin{tabular}{|c|c|c|c|}
\hline \multirow[b]{2}{*}{ Independent Variable } & BEHAVIOR & ATTRACTION & IDENTIFICATION \\
\hline & & & \\
\hline Nonmetro Residence $(-)^{\star \star}$ & 1.07 & 1.67 & 1.02 \\
\hline Full-time Work $(-)^{* *}$ & $0.48^{*}$ & 0.98 & 0.90 \\
\hline Education (-) & 1.03 & 0.93 & $0.71^{*}$ \\
\hline Health Condition $(+)^{\star \star *}$ & 1.05 & 1.15 & 1.12 \\
\hline Height (inches) (-) & 0.96 & 0.95 & 0.97 \\
\hline Weight (pounds) (-) & 1.00 & 1.00 & 1.00 \\
\hline Age $(+)$ & $0.83^{*}$ & 1.03 & 1.01 \\
\hline Ever Married $(-)^{* \star}$ & --- & $0.22^{*}$ & $0.59^{*}$ \\
\hline Ever Cohabited $(-)^{* *}$ & --- & 0.45 & 1.28 \\
\hline F-test & $(7,4263)=26.54^{*}$ & $(9,4261)=1.59$ & $(9,4261)=6.88^{*}$ \\
\hline
\end{tabular}

As hypothesized, male asexuals, according to the "identification" dimension, have significantly lower levels of education than sexuals; and full-time workers are less likely to be asexuals than sexuals, as measured on the "behavior" dimension. Health differences were not as notable for men as for women; among males this variable did not differentiate asexuals from sexuals in any of the three equations.

One difference in the male equations compared to the female equations was the importance of the ever-married characteristic. This variable had a significant effect in 
two of the male equations (attraction and identification) and, as just noted, the "nevermarried" response perfectly predicted the asexual response in the behavior equation, and was hence dropped as an independent variable.

Male asexuals tend to differ significantly from male sexuals in terms of education. These findings are similar to those for female asexuals. For other characteristics, however, the findings for male asexuals are more different than similar from those of female asexuals. We turn now to a discussion of the general implications of our research.

\section{Discussion and conclusion}

In this paper, we used data from the 2002 National Survey of Family Growth (NSFG) to assess the prevalence of asexuality among males and females in the United States, and to ascertain the extent to which asexuals differ from sexuals on a number of characteristics. Our review of the literature on asexuality revealed a diverse set of understandings about asexuality. Is an asexual an individual who does not engage in sexual behavior, one who experiences no sexual desire, one who calls him or herself an asexual, or some combination thereof? Due to the multitude of definitions of asexuality, we opted to conceptualize asexuality according to three features of sexuality, namely, one's behavior, one's desire, and one's self-identification (see Laumann et al. 1994). We initially categorized persons as asexual on the basis of any combination of these three dimensions. In our logistic regression analyses, however, we focused only on asexuals and sexuals defined separately on the basis of identification, or attraction, or behavior. This strategy was dictated by the small numbers of respondents in combinations of one or more of these dimensions. We found that conclusions about the prevalence of asexuality and the characteristics of asexuals versus sexuals differ depending on the asexuality dimension used.

As anticipated, the prevalence of asexuality among U.S. females and males is the highest when only asexual behavior is used as the criterion. Asexual behavior is defined in this analysis as never having sex in one's lifetime with either males or females. We found that almost $5 \%$ of females and more than $6 \%$ of males have never had sex at any time in their lives. But given that our sample of U.S. males and females is between the ages of 15 and 44, it is likely that some of these individuals not yet ever having sex will have sex at a later time.

The next highest level of prevalence of asexuality was indicated when only selfidentification is used, followed by the combination of behavior and self-identification. It is important, however, to reiterate that the "something else" category in the NSFG question pertaining to the identification of one's sexuality is surely an overinclusive 
measure of asexuality. Although we suggested that many self-identified asexuals would elect this category, we acknowledge that individuals with other types of sexual desires who do not fall into the heterosexual, homosexual, or bisexual categories would also choose this category. Due to budget constraints, the NSFG did not permit individuals who chose the "something else" category to specify their choice. This option is now offered on current and future cycles of the NSFG, so that individuals are now permitted to write in what they mean by "something else." This will hopefully allow for a more accurate analysis of asexual identification.

Our prevalence findings are quite similar to those of Bogaert (2004) when only the desire dimension is considered - the only asexuality dimension considered by him. Using the NSFG question dealing with sexual desire, we find the lowest prevalence of asexuality. Notably, individuals responded that they were unsure of their sexual attraction regardless of whether they were currently in a partnered relationship; this was particularly true for females. This supports the literature which suggests that some "asexuals" engage in sexual behavior and are in committed relationships, but do not experience sexual desire.

Nonetheless, we again observe that the "not sure" response to the sexual attraction question is an imperfect measure of asexuality. This is a proxy response for identifying asexuals, and the "not sure" response could certainly include some persons who are uncertain about whether they are more attracted to men or women, for example. This response category, much like the others used in this analysis, is of utility for our analyses because it includes those with asexual desire. It provides, however, what is likely an overestimate of those with asexual desire.

This analysis of prevalence rates of asexuality highlights the importance of considering sexuality across the three dimensions of behavior, identity, and desire. If one subscribes to an essentialist view of asexuality (that is, people either are or are not asexual on all three dimensions), very few females and males would be classified as asexual (Figures 1 and 2). In contrast, between $0.8 \%$ and $4.8 \%$ of females, and $0.7 \%$ and $6.1 \%$ of males, can be classified as asexual across the three dimensions separately. Thus, although a few individuals provided the so-called "asexual" response on all three dimensions, most of the respondents gave the asexual response on only a single dimension or on a combination of any two of the dimensions. This provides a more encompassing understanding of the prevalence of asexuality, and emphasizes the importance of a social constructionist approach.

Similarly, the degree to which asexuals differ from sexuals on various characteristics depends on the way asexuals are defined. Among females, asexuals defined only on the basis of behavior were found to differ from sexuals on five of the nine examined characteristics. But asexuals defined on the basis of desire differed from sexuals on only one of these characteristics. Among males, asexuals defined only on the 
basis of behavior differed from sexuals on two of the characteristics, plus two more that perfectly predicted the asexual category and hence needed to be dropped from the logistic regression equation. But when male asexuals were defined on the basis only of sexual desire, the logistic regression equation had an F-value that was not statistically significant.

An understanding of the prevalence of asexuality and its predictors, therefore, is highly dependent on the manner in which asexuality is defined. The particular manner in which one chooses to measure asexuality also depends on the particular research question. If a researcher is concerned with examining asexuality as a sexual identity, including the predictors of such an identity and outcomes associated with an asexual identity, then measuring asexuality using the identity dimension is appropriate. If, however, the interest concerns potential physical or social predictors that might contribute to a lack of sexual desire, then measuring asexuality using the identity dimension could be problematic. As reflected in Figure 1, of the 57 women who provided an asexual response on the desire question, only 20 provided an asexual response on the identity question. Thus, asexual identity could be a poor measure of asexuality for those more interested in the absence of sexual desire.

The finding that the prevalence and characteristics of asexuals vary across these three dimensions is much like those assessing other sexualities. Given that identification as gay or lesbian differs greatly from those who engage in same-sex sexual behavior (Laumann et al. 1994; Kinsey et al. 1948), for example, researchers must carefully consider their research question in light of the available measure of sexuality. To illustrate, for those interested in examining discrimination based on sexual orientation, a behavioral measure of sexual orientation is unlikely to yield a true indicator of discrimination given that behavior can be more masked than identity (see discussion in SMART 2009; Baumle et al. 2009).

Given the variation in both prevalence and characteristics of sexualities across these three dimensions, it is important to consider an incorporation of measures of all three dimensions in surveys involving sexuality. Our study of asexuals highlights this importance, both for those interested in the social and physical causes and implications of asexuality, as well as those examining other sexualities. 


\section{References}

Abbott, E. (2001). A History of Celibacy: From Athena to Elizabeth I, Leonardo da Vinci, Florence Nightingale, Ghandi, and Cher. New York: Scribner.

Baumle, A.K., Compton, D.R., and Poston, Jr., D.L. (2009). Same Sex Partners: The Demography of Sexual Orientation. Albany, NY: SUNY Press.

Blumstein, P. and Schwartz, P. (1983). American Couples: Money, Work, Sex. New York: William Morrow.

Bogaert, A.F. (2004). Asexuality: Prevalence and Associated Factors in a National Probability Sample. The Journal of Sex Research 41(3): 279-287.

Butler, J. (1990). Gender Trouble. New York: Routledge.

Cozzens, D. (2006). Freeing Celibacy. Collegeville, MN: Liturgical Press.

Deacon, S., Minichiello, V., and Plummer, D. (1995). Sexuality and Older People: Revisiting the Assumptions. Educational Gerontology 21(5): 497-513.

Earls, C.M. and Lalumiere, M.L. (2009). A Case Study of Preferential Bestiality. Archives of Sexual Behavior 38(4): 605-609.

Foucault, M. (1978). The History of Sexuality: An Introduction. Vol. 1. New York: Vintage Books.

Jay, D. (2005). Asexual Visibility and Education Network [electronic resource]. http://www.asexuality.org/info.htm.

Katz, J. (1995). The Invention of Heterosexuality. New York, NY: Penguin Books, Inc.

Kinsey, A.C., Pomeroy, W.B., and Martin, C.E. (1948). Sexual Behavior in the Human Male. Philadelphia, PA: W.B. Saunders and Company.

Laumann, E.O., Gagnon, J.H., Michael, R.T., and Michaels, S. (1994). The Social Organization of Sexuality: Sexual Practices in the United States. Chicago: The University of Chicago Press.

Milligan, M.S. and Neufeldt, A.H. (2001). The Myth of Asexuality: A Survey of Social and Empirical Evidence. Sexuality \& Disability 19(2): 91-109.

Mosher, W.D., Chandra, A., and Jones, J. (2005). Sexual Behavior and Selected Health Measures: Men and Women 15-44 Years of Age, United States, 2002. Advance Data From Vital and Health Statistics No. 362. Hyattsville, MD: National Center for Health Statistics. 
National Center for Health Statistics. (2004). National Survey of Family Growth, Cycle 6, 2002. CD-ROM Series 23, Number 4A. Hyattsville, Maryland: National Center for Health Statistics.

Nurius, P.S. (1983). Mental Health Implications of Sexual Orientation. The Journal of Sex Research 19(2): 119-136.

Prause, N. and Graham, C.A. (2003). Asexuality: A Preliminary Investigation [electronic resource]. http://www.asexuality.org/docs/SSSS_2003.ppt.

Prause, N. and Graham, C.A. (2007). Asexuality: Classification and Categorization. Archives of Sex Behavior 36: 341-356.

Rothblum, E.D. and Brehony, K.A. (1993). Why Focus on Romantic but Asexual Relationships among Lesbians? In: Rothblum, E.D. and Brehony, K.A. (eds.). Boston Marriages: Romantic But Asexual Relationships Among Contemporary Lesbians. Boston: The University of Massachusetts Press: 3-14.

Seidman, S. (1996). Introduction. In: Seidman, S. (ed.). Queer Theory/Sociology. Cambridge: Blackwell Publishers: 1-29.

SMART (Sexual Minority Assessment Research Team). (2009). Best Practices for Asking Questions about Sexual Orientation on Surveys. Los Angeles, CA: The Williams Institute, UCLA.

Sohn, A. (2005). Shifting to Neutral. New York Magazine March 7.

StataCorp (2009). Stata Statistical Software: Release 11.0. College Station, TX: Stata Corporation.

Westphal, S.P. (2004). Glad to be Asexual. New Scientist 17: 7. 